\title{
Glycan microarray reveal induced IgGs repertoire shift against a dietary carbohydrate in response to rabbit anti-human thymocyte therapy
}

\author{
Ron Amon ${ }^{1}$, Shani Leviatan Ben-Arye ${ }^{1}$, Limor Engler ${ }^{1}$, Hai Yu ${ }^{2}$, Noha Lim³ ${ }^{3}$, Ludmilla \\ Le Berre ${ }^{4,5}$, Kristina M. Harris' ${ }^{3}$, Mario R. Ehlers ${ }^{6}$, Stephen E. Gitelman', Xi Chen ${ }^{2}$, \\ Jean-Paul Soulillou ${ }^{4,5, *}$ and Vered Padler-Karavani ${ }^{1, *}$ \\ ${ }^{1}$ Department of Cell Research and Immunology, Tel Aviv University, Tel Aviv, Israel \\ ${ }^{2}$ Department of Chemistry, University of California-Davis, Davis, CA, USA \\ ${ }^{3}$ Biomarker Discovery Research, Immune Tolerance Network, Bethesda, MD, USA \\ ${ }^{4}$ Centre de Recherche en Transplantation et Immunologie UMR 1064, INSERM, Université de Nantes, Nantes, France \\ ${ }^{5}$ Institut de Transplantation Urologie Néphrologie (ITUN), CHU Nantes, Nantes, France \\ ${ }^{6}$ Clinical Trials Group, Immune Tolerance Network, San Francisco, CA, USA \\ ${ }^{7}$ Division of Pediatric Endocrinology and Diabetes, University of California San Francisco, San Francisco, CA, USA \\ * Co-senior authors \\ Correspondence to: Vered Padler-Karavani, email: vkaravani@post.tau.ac.il \\ Keywords: antibodies; anti-thymocyte globulin; human; N-glycolylneuraminic acid; sialic acids; Immunology \\ Received: September 19,2017 Accepted: November 14,2017 Published: December 11, 2017
}

Copyright: Amon et al. This is an open-access article distributed under the terms of the Creative Commons Attribution License 3.0 (CC BY 3.0), which permits unrestricted use, distribution, and reproduction in any medium, provided the original author and source are credited.

\section{ABSTRACT}

Humans have circulating antibodies against diverse glycans containing $\mathrm{N}$-glycolylneuraminic acid (Neu5Gc) due to function-loss mutation of the CMAH gene. This xenogenic non-human carbohydrate is abundant in red meat, xenografts and biotherapeutics. Low levels of diet-derived Neu5Gc is also present on normal human endothelial cells, and together with anti-Neu5Gc antibodies could potentially mediate "xenosialitis" chronic-inflammation. Rabbit anti-human thymocyte globulin (ATG) is a drug containing polyclonal IgG glycoproteins commonly used as an immunosuppressant in human transplantation and autoimmune diseases. In type-1 diabetes patients, infusion of Neu5Gc-glycosylated ATG caused increased global anti-Neu5Gc response. Here, for the first time we explore changes in antiNeu5Gc IgG repertoire following the immunization elicited by ATG, compared with the basal antibodies repertoire that reflect exposure to dietary-Neu5Gc. We used glycan microarrays with multiple Neu5Gc-glycans and controls to elucidate eventual differences in ATG-elicited repertoire, before/after ATG administration and track their kinetics (0, 1, 18 and 24 months). Response of all basal-pre-existing Neu5Gcspecific antibodies rapidly increased. This response peaked at one month post-ATG, with enhanced affinity, then resolved at 18-24 months. Induced-antibodies showed expanded diversity and de-novo recognition of different Neu5Gc-glycans, including endogenous glycolipids, that was further validated by affinity-purified anti-Neu5Gc antibodies from patients' sera. These findings strongly suggest that ATG-induced antiNeu5Gc IgGs represent a secondary exposure to this dietary carbohydrate-antigen in humans, with immune memory. Given their modified recognition patterns, ATGevoked anti-Neu5Gc antibodies could potentially mediate biological effects different from pre-existing antibodies. 


\section{INTRODUCTION}

Humans develop a comprehensive immune response against Neu5Gc, a foreign dietary sialic acid form, with significant potential implications on chronic inflammationmediated diseases such as cancer, atherosclerosis and xeno-transplantation [1-4]. Human anti-Neu5Gc antibodies behave differently from many other anti-carbohydrate antibodies [5]. These xeno-autoantibodies appear in infants coinciding with exposure to dietary Neu5Gc [6], are enhanced during disease [7,8], class switched switch from $\operatorname{IgM}$ to $\operatorname{IgG} / \operatorname{IgA}[9,10]$. Despite variable recognition profiles between human sera $[9,11]$, the levels can remain high for many years within the same individual [10]. Unlike other mammals, humans cannot hydroxylate cytidine 5'-monophosphate- $N$-acetylneuraminic acid (CMP-Neu5Ac) to synthesize Neu5Gc due to a specific gene loss-mutation. Instead, humans get exposed to Neu5Gc through dietary consumption of mammalian meat and dairy [1-4], and through biomedical exposure to Neu5Gc-glycosylated animal-derived tissues [2], biotherapeutics or bio-devices that are commonly used in the clinic $[4,12]$. While humans cannot synthesize Neu5Gc, dietary-Neu5Gc can nevertheless be absorbed by human cells with subsequent low level expression on the surface of endothelial cells and some epithelial cells generating xeno-auto-antigens [1]. The combination of circulating anti-Neu5Gc antibodies with accumulated Neu5Gc on human cells leads to a unique situation of chronic inflammation defined as 'xenosialitis' $[13,14]$, that had been suggested to exacerbate various human diseases [3]. Experimental xenoxialitis had been demonstrated in mice $[13,14]$, yet in humans it may be even more complex and could likely be affected by changes in anti-Neu5Gc repertoire, for example by antibodies elicited through a non-dietary route. Therefore, deciphering the nature and repertoire of bioterapeutic-elicited anti-Neu5Gc antibodies could be critical for understanding their possible role in the immunopathogenesis of related chronic-inflammation mediated diseases. Neu5Gc and Neu5Ac, that differ by a single oxygen, are the two major sialic acids forms in mammals, which are ubiquitously expressed at the tip of diverse carbohydrate chains (glycans) on glycoproteins and glycolipids [1, 15-17]. It is challenging to measure anti-Neu5Gc antibodies, because they recognize multiple Neu5Gc-glycan epitopes, on a large collection of Neu5Gccontaining sugar chains. This variety results from Neu5Gc attachment to diverse underlying sugar-chains, with different linkages, glycan conjugation to protein/ lipid-carriers and their diverse cell-surface density. To estimate overall anti-Neu5Gc response, a simple ELISA Inhibition Assay (EIA [7]) has been developed based on reactivity against multiple mouse Neu5Gc-containing glycoproteins, yet detailed information can only be achieved by measuring responses to distinct Neu5Gcglycans with Neu5Ac-glycans counterparts serving as controls, facilitated by large scale analysis using printed arrays $[9,18,19]$.

Rabbit anti-thymocyte globulin (ATG) is a polyclonal IgG preparation used for induction treatment of immunosuppression during various types of solid organ allografts, allogeneic stem cell transplants and autoimmune diseases [20]. These rabbit glycosylated antibodies carry determinants foreign to humans, including Neu5Gc-xenoantigens [4]. ATG therapy was administered to patients with new onset type-1 diabetes without additional immunosuppression in the START (Study of Thymoglobulin to ARrest Type 1 diabetes ) study, a phase II clinical trial (ClinicalTrials.gov \#NCT00515099) that aimed to evaluate its effect on preservation of $\beta$-cell function [21, 22]. In these patients, ELISA-EIA analysis revealed a significant increase of both global anti-Neu5Gc $\operatorname{IgM}$ and IgG after ATG treatment [23]. Here, we use glycan microarray to profile the kinetics, specificity, affinity and repertoire diversity of anti-Neu5Gc IgGs following ATG treatment. The top seven EIA-responders were analyzed over a large panel of Neu5Gc-glycans and Neu5Ac-glycans on microarrays. This revealed that the drug-induced anti-Neu5Gc response is dramatically different from the basal response, with a strong induction of all pre-existing anti-Neu5Gc IgGs, as well as newly developed IgG repertoires against diverse Neu5Gcglycans, with increased binding-affinity.

\section{RESULTS}

To investigate carbohydrate immune recognition in the context of anti-Neu5Gc response, we took advantage of the availability of serum samples from the seven START study participants $[21,22]$ that had the highest titers of anti-Neu5Gc IgG one month following the fourdays course of rabbit ATG treatment (ThymoglobulinGenzyme; day 1: $0.5 \mathrm{mg} / \mathrm{kg}$, days 2-4: $2 \mathrm{mg} / \mathrm{kg}$; without additional immunosuppressive agents) [23], as determined by EIA [7] (Table 1). ATG targets multiple T-cell antigens, and its immunosuppressive activity is largely associated to peripheral $\mathrm{T}$ cell depletion, however it also affects other cell types $[20,24]$.

For detailed profiling of anti-Neu5Gc immune responses we used a unique sialoglycan microarray with various Neu5Gc-glycans and control Neu5Ac-glycans, each covalently attached to epoxy-activated glass slides [7]. We focused on IgG response that had been suggested to mediate chronic inflammation diseases, and for this purpose used anti-human IgG specific secondary antibody that had been validated to lack cross reactivity with other human Ig isotypes (i.e. IgM, IgA). To characterize the kinetics of response to these diverse glycans we analyzed patients' serum samples obtained before-ATG [screening visit (-1), day of treatment ( 0 ; before administration)], and samples taken after treatment (at 1, 18 and 24 months). In all patients, there was a clear induction of highly-specific 
Table 1: Patients characteristics

\begin{tabular}{|l|l|}
\hline & Treatment \\
\hline & $(\mathrm{n}=7)$ \\
\hline Age in years & $20(7.8)$ \\
\hline $12-21$ years & $3(43 \%)$ \\
\hline $22-35$ years & $4(57 \%)$ \\
\hline Men & $4(57 \%)$ \\
\hline Ethnic origin & \\
\hline White & $6(86 \%)$ \\
\hline Non-white & $1(14 \%)$ \\
\hline Body-mass index & $22.4(2.2)$ \\
\hline Days since diagnosis & $62.7(24.4)$ \\
\hline Baseline 2-h C-peptide area under the curve $(\mathrm{pmol} / \mathrm{ml})$ & $0.764(0.219)$ \\
\hline $\begin{array}{l}\text { Anti-Neu5Gc IgG (ng/ } \mu \\
\text { 1)* }\end{array}$ & \\
\hline Baseline & $5.4(2.3)$ \\
\hline Month 1 & $212.4(368.9)$ \\
\hline
\end{tabular}

* Measure by EIA assay [7].

anti-Neu5Gc IgG response, with minimal/no recognition of control Neu5Ac-glycans (Figure 1), confirming previous EIA analysis [23]. Anti-Neu5Gc responses were increased vigorously, peaking at one month post-ATG infusion, then resolved at 18-24 months (Figure 1, Supplementary Figure 1). This exemplifies a long-term effect despite a short initial antigenic challenge, supporting previous studies in patients shortly exposed to animal-derived tissues [10]. At one month, all pre-ATG-M0 antibodies were elevated, and in addition, antibodies to new epitopes were detected in sera of most subjects, showing that ATGtreatment increased the repertoire diversity by eliciting $d e$ novo recognition of individual Neu5Gc-glycans (Figure 1A, Supplementary Figure 1B; for example, glycan ID $\# 73$ in S1-S3, and glycan IDs \#72, \#73, \#69, \#67, \#75 in S5). The most prominent examples of this were observed for S4/S5-microarrays (Figure 2A-2B). These newly generated anti-Neu5Gc IgGs were not detected prior to ATG treatment at month 0 , and recognized several monosialylated $\alpha 2-3 / 6$-linked glycans and the glycosphingolipid oligosaccharide $\quad \alpha 2$-8-linked Neu5Gc-di-sialylated glycan (ID\#75: Neu5Gc $\alpha 8$ Neu5Gc $\alpha 3$ Gal $\beta 4$ Glc $\beta O-$ Linker; Figure 2B). Importantly, this glycolipid-glycan recognition was highly specific with low cross-reactivity to other Neu5Gc-glycans, as demonstrated by differential reactivity-inhibition with glycan ID\#75 (Figure 3A). Glycolipid recognition was unexpected since ATG-IgGs are glycoproteins containing $N$-glycans that lack Sia $\alpha 2-8$, as determined by mass-spectrometry [4]. Lectin analysis showed ATG-IgGs carry both Sia 2 2-3 and Sia $2-6$, with HPLC-quantified Neu5Gc (3.1 \pm 0.05 pmole $/ \mu \mathrm{g}$ ATG) at $\sim 7$-fold over Neu5Ac (Supplementary Figure 2). At one month, the average total anti-Neu5Gc IgG response was dramatically enhanced in S4 by 7-fold and in S5 by 122fold (S4: $343 \pm 131$ to $2495 \pm 251$; S5: $142 \pm 52$ to 17338 \pm 2157 ; RFU mean \pm SE) (Figure 2B). In both S4 and S5, de novo induced anti-Neu5Gc IgGs peaked at one month post-ATG (M1), but only in S5 remained in circulation through 18-24 months (Figure 1), suggesting differences in the quality of the humoral response elicited by ATG in different individuals, and also that introduction of these animal-derived Neu5Gc-containing glycoproteins sometimes result in a long-lasting antibody exposure to new Neu5Gc-epitopes.

To directly compare the quality of pre-existing versus ATG-induced anti-Neu5Gc antibodies from these patients' sera, anti-Neu5Gc IgGs were affinity-purified. Sera were loaded on two sequential columns with the first containing Neu5Ac-glycoproteins, and the second containing Neu5Gc-glycoproteins, from which antiNeu5Gc antibodies were eluted with free Neu5Gc [9]. Due to expected low quantities of anti-Neu5Gc antibodies in pre-ATG sera (Figure 1), serum from all seven patients collected before ATG-treatment were pooled together for affinity-purification, yielding $3.2 \mu \mathrm{g} / \mathrm{ml}$ pooled sera (total $10 \mathrm{ml}$ ). At the one month time point, anti- 
Neu5Gc antibodies were affinity-purified from individual sera, resulting in $30.8 \pm 13.7 \mu \mathrm{g} / \mathrm{ml}$ sera (mean $\pm \mathrm{SE}$ ), demonstrating at least 10-14-fold more antibodies in the elicited response. These yields likely represent most antiNeu5Gc reactivity due to minimal residual-reactivity in the column flow-through after purification (data not shown). Glycan microarray analysis of these purified anti-Neu5Gc antibodies confirmed their high specificity towards all Neu5Gc-glycans, and not towards Neu5Acglycans (Figure 3B). These elevated antibody quantity yields at M1 compared to pooled pre-ATG levels were also associated with a major enhancement in reactivity, as exemplified in S4/S5 (Figure 2B).

To test whether the increased reactivity against various Neu5Gc-epitopes was also associated with enhanced binding strength, we evaluated the affinity equilibrium constant $\mathrm{K}_{\mathrm{D}}$. Due to limited sample availability, $K_{D}$ could not be determined from kinetic measurements (the ratio of the rate constants $\mathrm{k}_{\mathrm{d}} / \mathrm{k}_{\mathrm{a}}$ ). Instead it was estimated through glycan microarray analysis, by fitting a plot of response at equilibrium against a wide range of purified anti-Neu5Gc antibody concentrations, with a constant concentration of each of the printed Neu5Gc-glycans (at $100 \mu \mathrm{M}$ ). This arraytitration analysis of purified-antibodies suggest a $\sim 7$ fold increased IgG-affinity at S5-M1 versus pre-ATG (0.2-22.1-fold $\mathrm{K}_{\mathrm{D}}$ increase against individual Neu5Gcglycans; Figure 3C, Supplementary Table 2). To further evaluate the efficiency of affinity-purification to obtain the authentic pool of induced antibodies from each serum, we analyzed profiles of average Neu5Gc-glycans responses against specific Sia-linkages (Sia 2-3/6/8; Figure 3D). This confirmed the expanded repertoire diversity in elicited anti-Neu5Gc antibodies post-ATG. Furthermore, the affinity-purified antibodies maintained their unique serum-repertoire patterns, and their differences from
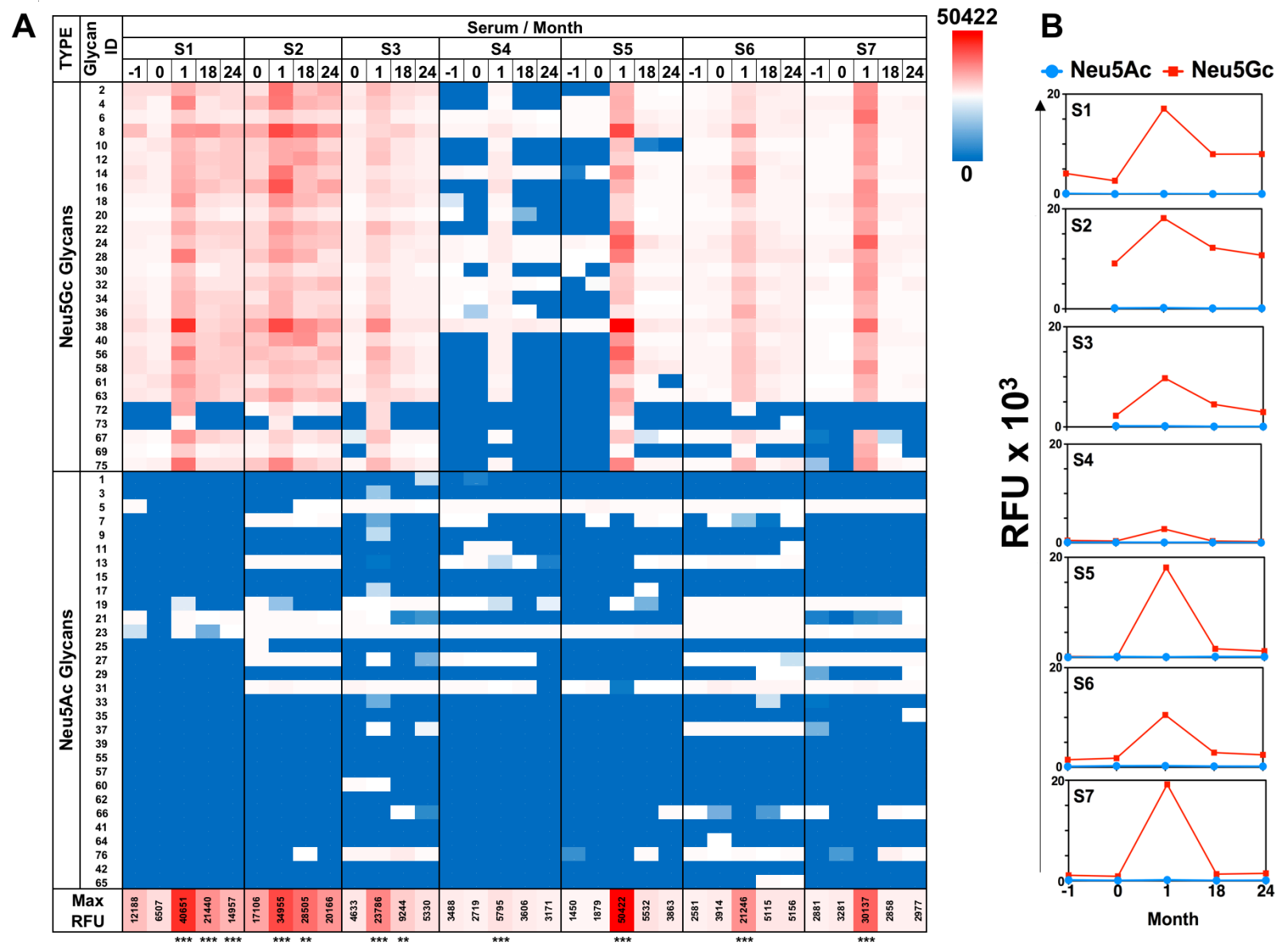

Figure 1: Diverse anti-Neu5Gc IgG response is induced after ATG treatment. A. Sequential sera samples pre-/post-ATG therapy were tested at 1:100 dilution on sialoglycan microarrays, then detected by Cy3-anti-human $\operatorname{IgG}(40 \mathrm{ng} / \mathrm{well})$. Relative fluorescence units (RFU) of all mono-sialylated Neu5Ac-glycans or Neu5Gc-glycans showed induction of highly specific anti-Neu5Gc response that peaked at one month post-ATG with some Neu5Gc-glycans responses sustained at 18-24 months post-ATG (Heatmap across all samples: red-white-blue represent maximum $-50^{\text {th }}$ percentile - minimum reactivity, respectively; minimum and maximum values are indicated in the figure; repeated measures One-Way ANOVA, ${ }^{* * *} P<0.0001$ significant between M0 and M1; detailed analysis described in Supplementary Figure 1A). Glycan structures are detailed in Supplementary Table 1. B. Average RFU of all mono-sialylated Neu5Ac-glycans (blue line) or Neu5Gc-glycans (red line) showed induction of highly specific anti-Neu5Gc response peaking one month post-ATG. 
other samples (Figure 3D). Likewise, correlation patterns between sera before/after purification remained the same (Figure 3E). Altogether, these data provide direct evidence that the short treatment with Neu5Gc-glycosylated foreign ATG not only causes a quantitative induction, but also a qualitative enhancement of highly specific anti-Neu5Gc IgGs, with improved affinities. Importantly, this highlyspecific and diverse induced response is not limited to Neu5Gc-antigens on ATG-protein-carriers, but can also recognize Neu5Gc-glycolipids, implying a recall response with activation of initially-quiescent memory.

\section{DISCUSSION}

Antibody secretion is initiated by activated-B cells that differentiate into short- or long-lived plasma cells. To diversify the repertoire of antigen-specific cells and optimize their affinity, activated-B cells transiently repress plasma cell (PC) differentiation followed by class-switch recombination (e.g. to $\mathrm{IgG}$ ), or that they enter the germinal center (GC) for somatic hypermutation and class-switch recombination to yield high-affinity clonal variants that differentiate into either quiescent memory-B cells or plasma cells [25]. Some GC-plasma cells turn into longlived plasma cells (LLPCs) in the bone marrow, where they do not proliferate, but act as long-term antibody factories $[25,26]$.
The enhanced and diverse anti-Neu5Gc immune response following Neu5Gc-ATG treatment is thus likely mediated by memory-B cells, that could include both quiescent memory-B cells and LLPCs. At one month, the dramatic increase in pre-existing anti-Neu5Gc IgGs is in contrast to the overall transient $\mathrm{B}$ cell depletion observed in these patients [21]. Furthermore, the increase in antiNeu5Gc IgGs repertoire-breadth, with de novo recognition patterns, supports the anamnestic involvement of quiescent memory-B cells that become activated upon re-exposure to Neu5Gc-glycosylated-ATG. This is further corroborated by the recognition of Neu5Gc-glycolipid glycans not expected to appear on ATG-glycoproteins.

This study was limited to antibody repertoires in patients' serum samples, lacking accessibility to blood cells in 'real time', yet the elaborated results strongly substantiate the existence of memory responses to the Neu5Gc-dietary carbohydrate antigen. Circulating antiNeu5Gc antibodies may contribute to exacerbation of chronic inflammation-mediated diseases [8, 27], including in cancer and vascular lesions [14, 28-31], but are also potential therapeutics or biomarkers [1, 3, 32]. Our findings provide the first description of the drug-elicited anti-Neu5Gc IgGs with different repertoires and affinities. These may contribute to as yet unidentified pathologies in patients exposed to high levels of such elicited-antibodies for long periods after stimulation with animal-derived
A

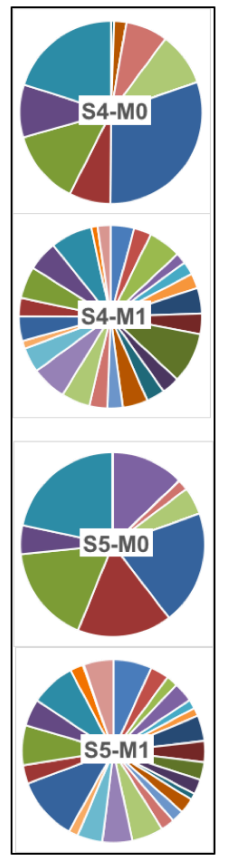

B

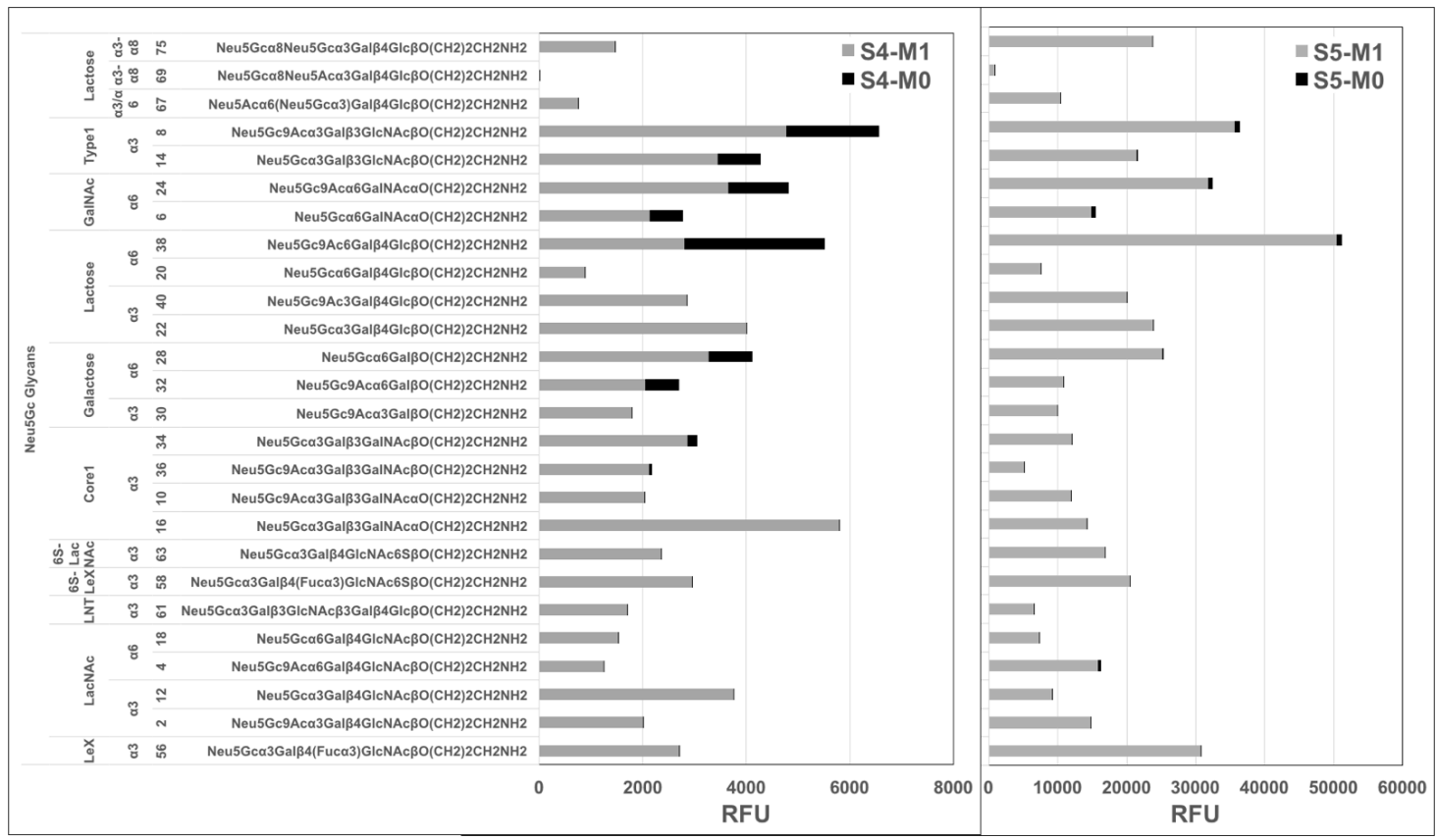

Figure 2: Diverse de novo anti-Neu5Gc IgGs repertoire post-ATG. A. Pie charts of anti-Neu5Gc IgG microarray recognition patterns against each Neu5Gc-glycan in S4 and S5 pre-ATG (M0) and post-ATG (M1) exemplifies increased diversity (each pie faction represents a different Neu5Gc-glycan, demonstrating increased number of Neu5Gc-glycans that are being recognized at M1 compared with M0 in each sera, reflected by increased number of pie fractions in M1). B. S4 and S5 RFU divided to common underlying core-glycanstructures demonstrate de novo recognition of additional Neu5Gc-glycans with strongly increased intensities. 
molecules or tissues [4, 12]. Drug-induced anti-Neu5Gc antibodies could potentially recognize integrated dietaryNeu5Gc on endothelial/epithelial cells [1, 3], and interfere with their proper functions. In this respect, our findings suggest that further investigation of induced anti-Neu5Gc antibodies is warranted, especially those being elicited in patients challenged with animal-derived drugs, grafts, tissues or bioprosthetic devices.

\section{MATERIALS AND METHODS}

\section{Human sera samples}

Seven patients' sera were obtained from the START study (Gitelman et al., 2013) (Table 1) and used in accordance with the Helsinki declaration and Tel Aviv University Institutional Review Board.

\section{Antibodies}

Neu5Gc IgY (Biolegend), biotinylated-SNA and biotinylated-MAL-II (Vector Labs), HRP-donkey-antichicken IgY, HRP-Streptavidin and Cy3-goat-anti-human$\operatorname{IgG}(\mathrm{H}+\mathrm{L})$ (Jackson ImmunoResearch).

\section{Affinity purification of anti-Neu5Gc antibodies from human sera}

Antibodies were purified as previously described [9]. The sera of all seven patients at M(-1) and M0 were
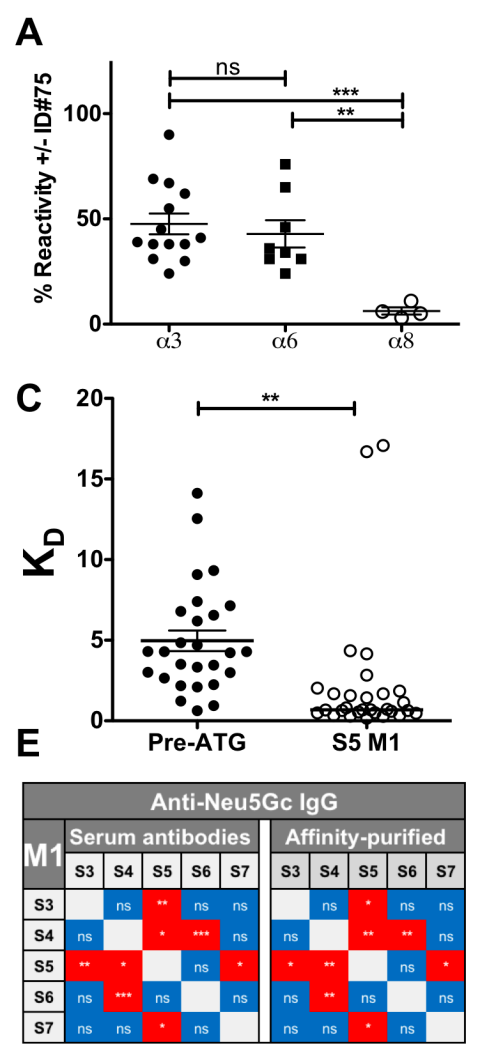

B

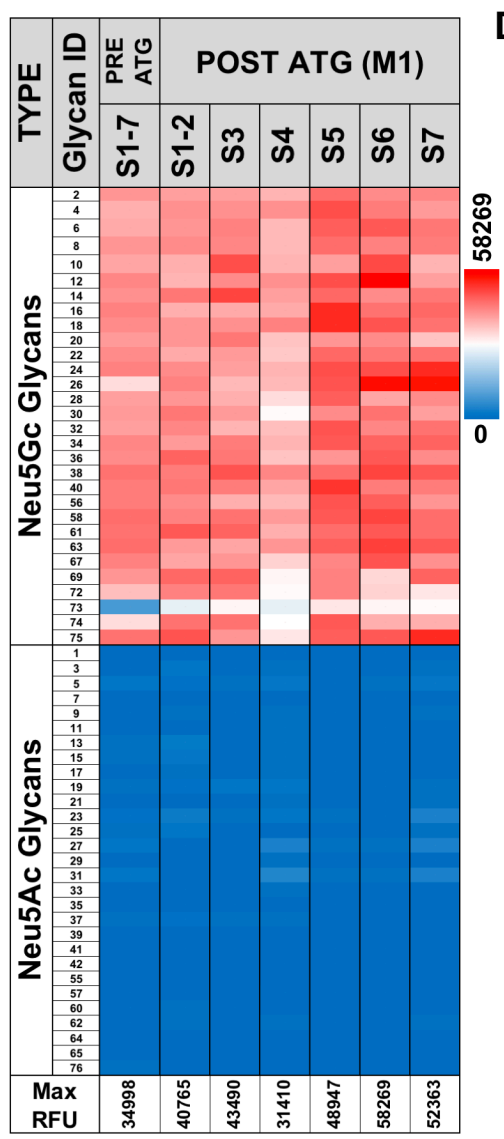

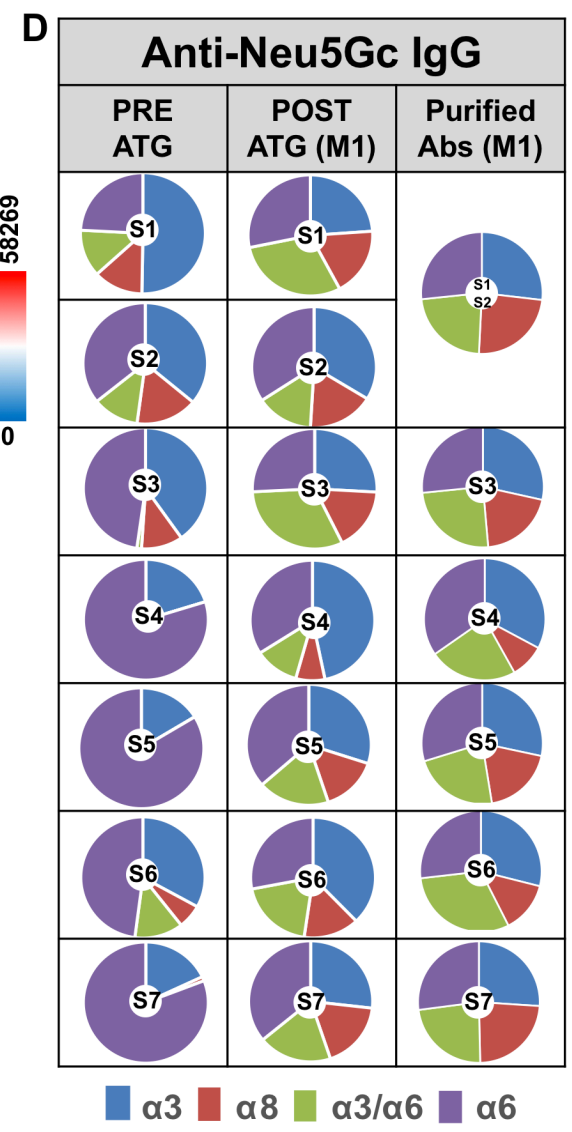

Figure 3: Characterization of affinity-purified anti-Neu5Gc IgGs pre- and post-ATG. A. Anti-Neu5Gc antibodies were affinity-purified from pooled pre-ATG or S5-M1 sera then $1 \mu \mathrm{g} /$ well each analyzed by sialoglycan microarrays, in the presence or absence of $0.5 \mathrm{mM}$ of competing glycan ID\#75 (Neu5Gc $\alpha 8 \mathrm{Neu} 5 \mathrm{Gc} \alpha 3 \mathrm{Gal} \beta 4 \mathrm{Glc} \beta \mathrm{O}$-Linker), followed by detection with Cy3-anti-human IgG (40 $\mathrm{ng} /$ well). Reactivity against glycolipid-glycans $(\alpha 8)$ is greatly inhibited compared to others $(\alpha 3 / 6)$ (One-way AVONA, Bonferroni posttest, $p=0.0012)$. B. Affinity-purified antibodies tested at $1 \mu \mathrm{g} /$ well followed by Cy3-anti-human IgG confirmed high Neu5Gc-specificity (Heatmap across all samples). C. To evaluate affinities of purified anti-Neu5Gc antibodies from pre-ATG versus S5-M1 sera, IgGs reactivity was tested at 14 quartile-serial dilutions and $\mathrm{K}_{\mathrm{D}}$-values/glycan calculated, demonstrating increased affinities post-ATG (medians; non-linear fit with one-site specific binding; Table S2). D. Pie charts of anti-Neu5Gc-IgG divided by Sia-linkages reveals increased diversity pre-/ post-ATG, that is maintained after affinity-purification. Charts represent average response against Neu5Gc-glycans with Sia $2-3$ linkage ( $\alpha 3)$, Sia $\alpha 2-6$ linkage $(\alpha 6)$, glycolipid-type di/tri-sialylated with Sia $\alpha 2-8$ linkage $(\alpha 8)$, or the branched di-Sia $(\alpha 3 / 6)$. E. Similar correlation of anti-Neu5Gc IgG at M1-post-ATG before/after affinity-purification between patients (Pearson, Two-tailed, 95\% CI), supporting efficient affinity-purification. 
pooled resulting in $32.3 \mu \mathrm{g}$ of the pooled $10 \mathrm{ml}$. Yields of sera at the peak response (M1) were $73.8 \mu \mathrm{g} / \mathrm{ml} \mathrm{S} 1-\mathrm{S} 2$ (221.4 $\mu \mathrm{g}$ of $3 \mathrm{ml}$ pooled S1 and S2), $73.3 \mu \mathrm{g} / \mathrm{ml} \mathrm{S} 3$ (183.1 $\mu \mathrm{g}$ of $2.5 \mathrm{ml}), 6.7 \mu \mathrm{g} / \mathrm{ml} \mathrm{S} 4(13.4 \mu \mathrm{g}$ of $2 \mathrm{ml}), 18.4 \mu \mathrm{g} / \mathrm{ml}$ S5 $(36.8 \mu \mathrm{g}$ of $2 \mathrm{ml}), 7.5 \mu \mathrm{g} / \mathrm{ml} \mathrm{S6}(1.87 \mu \mathrm{g}$ of $0.25 \mathrm{ml})$, and $4.9 \mu \mathrm{g} / \mathrm{ml} \mathrm{S} 7(9.8 \mu \mathrm{g}$ of $2 \mathrm{ml})$.

\section{Sialoglycan microarray fabrication}

Arrays were fabricated with NanoPrint LM-60 Microarray Printer (Arrayit) on epoxide-derivatized slides (Corning 40044), at 70\% humidity, with four SMP3 pins (Arrayit) at sixteen $20 \times 20$ sub-arrays on each slide (Version 2.0). Each glycoconjugate printed in $100 \mu \mathrm{M}$ of optimized print buffer (300 mM phosphate buffer, $\mathrm{pH}$ 8.4). Next, slides were packed, vacuum-sealed and stored at room temperature (RT) until used.

\section{Sialoglycan microarray binding assay}

Slides were developed and analyzed as previously described [7] with some modifications. Slides were rehydrated with $\mathrm{ddH}_{2} \mathrm{O}$ and incubated for $30 \mathrm{~min}$ in a staining dish with $50{ }^{\circ} \mathrm{C}$ pre-warmed ethanolamine $(0.05$ $\mathrm{M})$ in Tris- $\mathrm{HCl}(0.1 \mathrm{M}, \mathrm{pH} 9.0)$ to block the remaining reactive epoxy groups on the slide surface, then washed with $50{ }^{\circ} \mathrm{C}$ pre-warmed $\mathrm{dd}_{2} \mathrm{O}$. Slides were centrifuged at $200 \times g$ for three min then fitted with ProPlate ${ }^{\mathrm{TM}}$ MultiArray 16-well slide module (Invitrogen) to divide into the sub-arrays (blocks). Slides were washed with PBST (0.1 $\%$ Tween 20), aspirated and blocked with $200 \mu \mathrm{l} /$ sub-array of blocking buffer (PBS/OVA, 1\% w/v ovalbumin, in PBS, $\mathrm{pH}$ 7.3) for 1 hour at RT with gentle shaking. Next, the blocking solution was aspirated and $100 \mu \mathrm{l} /$ block of 1:100 diluted sera or purified anti-Neu5Gc antibodies in $10 \mathrm{ng} /$ $\mu l$ diluted in PBS/OVA were incubated with gentle shaking for 2 hours at RT. Slides were washed three times with PBST, then with PBS for 2 min. Bound antibodies were detected by incubating with secondary detection diluted in PBS, $200 \mu \mathrm{l} /$ block at RT for 1 hour, Cy3-anti human IgG $1.2 \mu \mathrm{g} / \mathrm{ml}$ (Jackson Immunoresearch). Slides were washed three times with PBST then with PBS for 10 min followed by removal from ProPlate ${ }^{\mathrm{TM}}$ Multi-Array slide module and immediately dipping in a staining dish with $\mathrm{ddH}_{2} \mathrm{O}$ for 10 min with shaking, then centrifuged at $200 \times g$ for $3 \mathrm{~min}$ and scanned immediately.

\section{Array slide processing}

Processed slides were scanned and analyzed as described at $10 \mu \mathrm{m}$ resolution with a Genepix 4000B microarray scanner (Molecular Devices) at 350 gain. Image analysis was carried out with Genepix Pro 6.0 analysis software (Molecular Devices). Spots were defined as circular features with a variable radius using with local background subtraction.

\section{Affinity equilibrium constant KD calculation by microarray}

Slides were developed as described above with serial quarterly dilutions of purified S5-M1 or purified pooled Pre-ATG antibodies at $10 \mathrm{ng} / \mu \mathrm{l}-1.49 \times 10^{-7} \mathrm{ng} /$ $\mu \mathrm{l}\left(66.6 \mathrm{nM}-9.93 \times 10^{-7} \mathrm{nM}\right)$ in PBS/OVA blocking buffer. $\mathrm{K}_{\mathrm{D}}$ was calculated by fitting a plot of response at equilibrium against a wide range of purified anti-Neu5Gc antibody concentrations (12-13 dilutions, from $9.93 \times 10^{-7}$ $\mathrm{nM}$ up to $4.16 \mathrm{nM}$ or $16.6 \mathrm{nM}$, in S5-M1 and pooled PreATG, respectively; non-linear fit with one-site specific binding, GraphPad Prism 6.0).

\section{Selective inhibition with glycan ID \#75 by microarray}

Slides were developed as described with the following modifications. Purified $10 \mathrm{ng} / \mu \mathrm{l}$ of S5-M1 were pre-incubated in the presence or absence of $0.5 \mathrm{mM}$ glycan ID \#75 in PBS/OVA blocking buffer for 2 hours on ice prior to loading on the slide for development.

\section{Sialic acid detection by ELISA}

Sialic acids were detected on ATG by ELISA as previously described [9]. ATG was coated in duplicates at $1 \mu \mathrm{g} /$ well in $50 \mathrm{mM}$ sodium carbonate-bicarbonate buffer, pH 9.5 onto 96-well microtiter plates (Costar, Corning) and plates were incubated overnight at $4{ }^{\circ} \mathrm{C}$. Wells were blocked for 1 hour at room temperature with blocking buffer (PBS pH 7.4, 1\% ovalbumin), then aspirated and incubated with diluted primary antibody $100 \mu \mathrm{l} /$ well in the same blocking buffer for two hours at room temperature (chicken anti-Neu5Gc IgY at 1:7000, biotinylated SNA or MAL-II at $1 \mu \mathrm{g} / \mathrm{ml})$. The plates were washed three times with PBST (PBS pH 7.4, 0.1\% Tween-20) and subsequently incubated for 1 hour at RT with HRPconjugated secondary antibody in PBS (HRP-donkey-antichicken IgY $0.26 \mu \mathrm{g} / \mathrm{ml}$ and HRP-streptavidin $0.09 \mu \mathrm{g} / \mathrm{ml}$, respectively). After washing three times with PBST, wells were developed with $140 \mu \mathrm{l}$ of $O$-phenylenediamine in 100 $\mathrm{mM}$ citrate- $\mathrm{PO}_{4}$ buffer, $\mathrm{pH} 5.5$, and the reaction stopped with $40 \mu \mathrm{lof} \mathrm{H}_{2} \mathrm{SO}_{4}(4 \mathrm{M})$. Absorbance was measured at $490 \mathrm{~nm}$ on SpectraMax M3 (Molecular Devices). Specific binding was defined by subtracting the background readings obtained with the secondary antibody only on coated wells. 


\section{Sialic acid analysis by DMB-HPLC}

Sia content in ATG was analyzed as previously described [33]. Sias were released from glycoconjugates by acid hydrolysis with $0.1 \mathrm{M}$ of $\mathrm{H}_{2} \mathrm{SO}_{4}$ for 1.5 hours at $80{ }^{\circ} \mathrm{C}$, then neutralized with $0.1 \mathrm{M}$ of $\mathrm{NaOH}$. Free Sias were then derivatized with 1, 2-diamino-4, 5 -methylenedioxybenzene (DMB; Sigma) for 2.5 hours at $50{ }^{\circ} \mathrm{C}$, separated by Microcon-10 centrifugal filters and analyzed by fluorescence detection on reverse-phase high pressure liquid chromatography (DMB-HPLC; Hitachi HPLC Chromaster). HPLC run was on C18 column (Phenomenex C18 Gemini $250 \times 4.6 \mathrm{~mm}$ ) at $24{ }^{\circ} \mathrm{C}$ in running buffer $\left[84.5 \% \mathrm{ddH}_{2} \mathrm{O}, 8.5 \%\right.$ acetonitrile, $7 \%$ methanol (Merck)] for 60 minutes (min) at a flow rate of $0.9 \mathrm{ml} / \mathrm{min}$. Quantification of Sias was done in comparison with known quantities of DMB-derivatized Neu5Ac.

\section{Statistical analysis}

Statistical analyses were performed using GraphPad Prism 5.0 or 6.0, and described in context in the figure legends. P-value less than 0.05 was considered statistically significant.

\section{Author contributions}

VPK, JPS and RA designed the experiments and wrote the manuscript. NL, KMH, MRH, SEG and XC provided critical reagents. RA conducted the experiments with assistance of SLBA and LE. All authors reviewed the manuscript.

\section{ACKNOWLEDGMENTS}

The authors appreciate the helpful comments and critiques provided by Prof. Adit Ben-Baruch, Tel Aviv University.

\section{CONFLICTS OF INTEREST}

The authors have no conflicts of interest to disclose.

\section{FUNDING}

This work was supported by a grant from The Israeli Ministry of Science, Technology and Space No. 62466 and European Union H2020 Program grants (ERC2016-STG-716220) (to V.P-K), and The 7th Framework Program FP7-Health-2013-INNOVATION-1-603049 of the European Commission (to V.P-K, J-P.S. and X.C.).

\section{REFERENCES}

1. Amon R, Reuven EM, Leviatan Ben-Arye S, PadlerKaravani V. Glycans in immune recognition and response. Carbohydr Res. 2014; 389:115-122.

2. Salama A, Evanno G, Harb J, Soulillou JP. Potential deleterious role of anti-Neu5Gc antibodies in xenotransplantation. Xenotransplantation. 2015; 22:85-94.

3. Alisson-Silva F, Kawanishi K, Varki A. Human risk of diseases associated with red meat intake: Analysis of current theories and proposed role for metabolic incorporation of a non-human sialic acid. Mol Aspects Med. 2016; 51:16-30.

4. Couvrat-Desvergnes G, Salama A, Le Berre L, Evanno G, Viklicky O, Hruba P, Vesely P, Guerif P, Dejoie T, Rousse J, Nicot A, Bach JM, Ang E, et al. Rabbit antithymocyte globulin-induced serum sickness disease and human kidney graft survival. J Clin Invest. 2015; 125:4655-4665.

5. Heimburg-Molinaro J, Lum M, Vijay G, Jain M, Almogren A, Rittenhouse-Olson K. Cancer vaccines and carbohydrate epitopes. Vaccine. 2011; 29:8802-8826.

6. Taylor RE, Gregg CJ, Padler-Karavani V, Ghaderi D, Yu H, Huang S, Sorensen RU, Chen X, Inostroza J, Nizet V, Varki A. Novel mechanism for the generation of human xeno-autoantibodies against the nonhuman sialic acid N-glycolylneuraminic acid. J Exp Med. 2010; 207:16371646.

7. Padler-Karavani V, Tremoulet AH, Yu H, Chen X, Burns JC, Varki A. A simple method for assessment of human anti-Neu5Gc antibodies applied to Kawasaki disease. PLoS One. 2013; 8:e58443.

8. Le Berre L, Rousse J, Gourraud PA, Imbert-Marcille BM, Salama A, Evanno G, Semana G, Nicot A, Dugast E, Guérif P, Adjaoud C, Freour T, Brouard S, et al. Decrease of blood anti- $\alpha 1,3$ Galactose Abs levels in multiple sclerosis (MS) and clinically isolated syndrome (CIS) patients. Clin Immunol. 2017; 180:128-135.

9. Padler-Karavani V, Yu H, Cao H, Chokhawala H, Karp F, Varki N, Chen X, Varki A. Diversity in specificity, abundance, and composition of anti-Neu5Gc antibodies in normal humans: potential implications for disease. Glycobiology. 2008; 18:818-830.

10. Scobie L, Padler-Karavani V, Le Bas-Bernardet S, Crossan C, Blaha J, Matouskova M, Hector RD, Cozzi E, Vanhove B, Charreau B, Blancho G, Bourdais L, Tallacchini M, et al. Long-term IgG response to porcine Neu5Gc antigens without transmission of PERV in burn patients treated with porcine skin xenografts. J Immunol. 2013; 191:2907-2915.

11. Gao B, Long C, Lee W, Zhang Z, Gao X, Landsittel D, Ezzelarab M, Ayares D, Huang Y, Cooper DKC, Wang Y, Hara H. Anti-Neu5Gc and anti-non-Neu5Gc antibodies in healthy humans. PLoS One. 2017; 12:e0180768.

12. Ghaderi D, Taylor RE, Padler-Karavani V, Diaz S, Varki A. Implications of the presence of $\mathrm{N}$-glycolylneuraminic acid in recombinant therapeutic glycoproteins. Nat Biotechnol. 
2010; 28:863-867.

13. Samraj AN, Läubli H, Varki N, Varki A. Involvement of a non-human sialic Acid in human cancer. Front Oncol. 2014; 4:33.

14. Samraj AN, Pearce OM, Läubli H, Crittenden AN, Bergfeld AK, Banda K, Gregg CJ, Bingman AE, Secrest P, Diaz SL, Varki NM, Varki A. A red meat-derived glycan promotes inflammation and cancer progression. Proc Natl Acad Sci U S A. 2015; 112:542-547.

15. Varki A, Schnaar RL, Schauer R. Sialic Acids and Other Nonulosonic Acids. In: Varki A, Cummings RD, Esko JD, Stanley P, Hart GW, Aebi M, Darvill AG, Kinoshita T, Packer NH, Prestegard JH, Schnaar RL, Seeberger PH, eds. Essentials of Glycobiology. Cold Spring Harbor (NY): Cold Spring Harbor Laboratory Press, 2015.

16. Inoue S, Sato C, Kitajima K. Extensive enrichment of N-glycolylneuraminic acid in extracellular sialoglycoproteins abundantly synthesized and secreted by human cancer cells. Glycobiology. 2010; 20:752-762.

17. Varki A. Colloquium paper: uniquely human evolution of sialic acid genetics and biology. Proc Natl Acad Sci USA. 2010; 107:8939-46.

18. Deng L, Chen X, Varki A. Exploration of sialic Acid diversity and biology using sialoglycan microarrays. Biopolymers. 2013; 99:650-665.

19. Leviatan Ben-Arye S, Yu H, Chen X, Padler-Karavani V. Profiling Anti-Neu5Gc IgG in Human Sera with a Sialoglycan Microarray Assay. J Vis Exp. 2017; 125: e56094.

20. Mohty M. Mechanisms of action of antithymocyte globulin: T-cell depletion and beyond. Leukemia. 2007; 21:13871394.

21. Gitelman SE, Gottlieb PA, Rigby MR, Felner EI, Willi SM, Fisher LK, Moran A, Gottschalk M, Moore WV, Pinckney A, Keyes-Elstein L, Aggarwal S, Phippard D, et al, and START Study Team. Antithymocyte globulin treatment for patients with recent-onset type 1 diabetes: 12-month results of a randomised, placebo-controlled, phase 2 trial. Lancet Diabetes Endocrinol. 2013; 1:306-316.

22. Gitelman SE, Gottlieb PA, Felner EI, Willi SM, Fisher LK, Moran A, Gottschalk M, Moore WV, Pinckney A, KeyesElstein L, Harris KM, Kanaparthi S, Phippard D, et al, and ITN START Study Team. Antithymocyte globulin therapy for patients with recent-onset type 1 diabetes: 2 year results of a randomised trial. Diabetologia. 2016; 59:1153-1161.

23. Salama A, Evanno G, Lim N, Rousse J, Le Berre L, Nicot A, Bach JM, Brouard S, Harris KM, Ehlers MR, Gitelman SE, Soulillou JP. Anti-Gal and Anti-Neu5Gc Responses in Nonimmunosuppressed Patients After Treatment With Rabbit Antithymocyte Polyclonal IgGs. Transplantation. 2017; 101:2501-2507.

24. Zand MS, Vo T, Huggins J, Felgar R, Liesveld J, Pellegrin T, Bozorgzadeh A, Sanz I, Briggs BJ. Polyclonal rabbit antithymocyte globulin triggers B-cell and plasma cell apoptosis by multiple pathways. Transplantation. 2005; 79:1507-1515.

25. Corcoran LM, Tarlinton DM. Regulation of germinal center responses, memory B cells and plasma cell formation-an update. Curr Opin Immunol. 2016; 39:59-67.

26. Leavy O. Immune memory: Sequential evolution of B cell memory. Nat Rev Immunol. 2016; 16:72-73.

27. Kavaler S, Morinaga H, Jih A, Fan W, Hedlund M, Varki A, Kim JJ. Pancreatic beta-cell failure in obese mice with human-like CMP-Neu5Ac hydroxylase deficiency. FASEB J. 2011; 25:1887-1893.

28. Hedlund M, Padler-Karavani V, Varki NM, Varki A. Evidence for a human-specific mechanism for diet and antibody-mediated inflammation in carcinoma progression. Proc Natl Acad Sci U S A. 2008; 105:18936-18941.

29. Padler-Karavani V, Hurtado-Ziola N, Pu M, Yu H, Huang S, Muthana S, Chokhawala HA, Cao H, Secrest P, FriedmannMorvinski D, Singer O, Ghaderi D, Verma IM, et al. Human xeno-autoantibodies against a non-human sialic acid serve as novel serum biomarkers and immunotherapeutics in cancer. Cancer Res. 2011; 71:3352-3363.

30. Pearce OM, Laubli H, Verhagen A, Secrest P, Zhang J, Varki NM, Crocker PR, Bui JD, Varki A. Inverse hormesis of cancer growth mediated by narrow ranges of tumordirected antibodies. Proc Natl Acad Sci U S A. 2014; 111:5998-6003

31. Pham T, Gregg CJ, Karp F, Chow R, Padler-Karavani V, Cao H, Chen X, Witztum JL, Varki NM, Varki A. Evidence for a novel human-specific xeno-auto-antibody response against vascular endothelium. Blood. 2009; 114:5225-5235.

32. Okerblom J, Varki A. Biochemical, Cellular, Physiological, and Pathological Consequences of Human Loss of N-Glycolylneuraminic Acid. ChemBioChem. 2017; 18:1155-71.

33. Padler-Karavani V, Song X, Yu H, Hurtado-Ziola N, Huang S, Muthana S, Chokhawala HA, Cheng J, Verhagen A, Langereis MA, Kleene R, Schachner M, de Groot RJ, et al. Cross-comparison of protein recognition of sialic acid diversity on two novel sialoglycan microarrays. J Biol Chem. 2012; 287:22593-22608. 